\title{
AFRIAT'S THEOREM FOR GENERAL BUDGET SETS
}

\author{
FRANÇOISE FORGES \\ ENRICO MINELLI
}

CESIFO WORKING PAPER NO. 1703

CATEGORY 9: INDUSTRIAL ORGANISATION

APRIL 2006

\footnotetext{
An electronic version of the paper may be downloaded

- from the SSRN website:

www.SSRN.com

- from the RePEc website:

www.RePEc.org

- from the CESifo website:

www.CESifo-aroup.de
} 


\title{
AFRIAT'S THEOREM FOR GENERAL BUDGET SETS
}

\begin{abstract}
Afriat (1967) showed the equivalence of the strong axiom of revealed preference and the existence of a solution to a set of linear inequalities. From this solution he constructed a utility function rationalizing the choices of a competitive consumer. We extend Afriat's theorem to a class of nonlinear budget sets. We thereby obtain testable implications of rational behavior for a wide class of economic environments, and a constructive method to derive individual preferences from observed choices. In an application to market games, we identify a set of observable restrictions characterizing Nash equilibrium outcomes.
\end{abstract}

JEL Code: D11, D43, C72.

Keywords: GARP, rational choice, revealed preferences, market games, SARP, WARP.

\author{
Françoise Forges \\ CEREMADE \\ University of Paris-Dauphine \\ Place du Maréchal de Lattre de Tassigny \\ 75775 Paris Cedex 16 \\ France \\ francoise.forges@dauphine.fr
}

\author{
Enrico Minelli \\ Department of Economic Sciences \\ University of Brescia \\ Italy \\ minelli@eco.unibs.it
}

March, 2006

We thank Sydney Afriat, Felix Kubler, Jean François Mertens and Heracles Polemarchakis for useful conversations. 


\section{INTRODUCTION}

Samuelson (1938) proposed the theory of revealed preference as a new, entirely behavioral foundation for the analysis of the competitive consumer. He opened a new field of investigation by asking which conditions the consumer's observed behavior should satisfy to be rationalized, i.e. interpreted as the outcome of the maximization of a preference relation. He also provided a first, partial answer in terms of the Weak Axiom of Revealed Preference, WARP. The theory was further developed by Houthakker (1950), who identified the Strong Axiom of Revealed Preference, SARP, as a necessary and sufficient condition for rationalization.

Richter (1966) observed that Samuelson's and Houthakker's ideas were relevant for any problem of choice, much beyond the case of a consumer choosing consumption bundles at given, fixed prices. He developed an abstract version of the theory, allowing for 'budget sets' which are just non empty subsets of a given universal set of possible choices. In his Theorem 1 he proved that (a suitably generalized version of) the SARP is necessary and sufficient for the existence of a rationalizing preference, even in this extremely general setting. The proof is non constructive, using Zorn's Lemma.

Almost at the same time, Afriat (1967) developed revealed preference theory in a completely different direction. In the original context of the competitive consumer, he emphasized the operational aspects of the theory. He took as data a finite number of observations, each one consisting of the chosen bundle of goods and the prevailing prices, and proved that, if these data satisfy the SARP, a rationalizing utility can explicitly be constructed by elementary linear programming techniques.

Afriat's method has subsequently been expanded and refined, notably by Diewert (1973), Varian (1982) and most recently Fostel, Scarf and Todd (2004). All these contributions deal with the case of linear, competitive budgets, and remain firmly in Afriat's constructive, finite observations setting.

Another important theoretical development, which can also be ascribed to the line of research initiated by Afriat, is the approximation theory of Mas Colell (1978). He asks whether increasing in a regular way the number of observations one can fully identify the underlying preference of the consumer. Again for the case of linear competitive budgets, Mas Colell identifies conditions for a positive answer.

Samuelson's original ideas have thus been pursued in two quite different directions: Richter's very general, non constructive existence results, and, for the special case of competitive linear budgets, Afriat's 
constructive approach, supplemented by Mas Colell's analysis of uniqueness and approximation.

Our contribution in this paper is to identify a class of choice problems which is much more general than the competitive consumer's and still retains sufficient structure to allow us to recover the exact analog of Afriat's and Mas Colell's results. We develop each of these extensions in the next two sections of the paper.

Our choice space is the positive orthant of some euclidean space, and we allow as admissible budgets all subsets of the choice space that can be obtained as the comprehensive closure of a compact set. Every budget in this class admits a description by means of an increasing continuous function (Lemma 1), and this allows us to obtain the analog of the Afriat's inequalities (Proposition 1).

Our class of budgets includes those considered by Matzkin (1991) and Chavas and Cox (1993), the only two papers, to the best of our knowledge, providing constructive rationalizations for the case of possibly non linear budgets. In both papers, the authors impose convexity assumptions, and in Proposition 2 (and the discussion thereof) we illustrate how our approach improves on their results.

Propositions 3 and 4 in the second section, on identification and approximation, are the analog in our setting of Mas Colell's results.

Besides its theoretical interest, the extension of Afriat's theory to our class of budgets may be relevant for applications. As an illustration, in the last section of the paper we use it to derive a set of testable implications of Nash behavior for a broad class of market games (Proposition $5)$.

\section{Existence of a Rationalization}

Consider an individual choosing consumption bundles in $R_{+}^{L}$. A consumption experiment is a finite collection $\left(x_{k}, B_{k}\right)_{k=1, \ldots n}$, where $x_{k} \in B_{k}$ and $B_{k} \subset R_{+}^{L}$. The interpretation is that $x_{k}$ is the observed choice of the individual when she has access to the set of consumption bundles $B_{k}$. We consider sets of alternatives of the form $B_{k}=\left\{x \in R_{+}^{L} \mid g_{k}(x) \leq 0\right\}$ with $g_{k}: X \rightarrow R$ an increasing, continuous function and $g_{k}\left(x_{k}\right)=0$, for all $k=1, \ldots n$.

Let $B^{\prime} \subset R^{L}$ be closed, compactly generated ${ }^{1}$, comprehensive ${ }^{2}$ and such that $0 \in \operatorname{Int}\left(B^{\prime}\right)$. We will show that our admissible sets of alternatives include all the sets obtained as $B=B^{\prime} \cap R_{+}^{L}$, where $B^{\prime}$ has the previous

\footnotetext{
${ }^{1} \exists K \subset R^{L}$, compact, such that $x \in B^{\prime}$ implies $\exists y \in K \cap B^{\prime}, x \leq y$.

${ }^{2} \forall y \in R^{L}$, if $\exists x \in B^{\prime}, y \leq x$, then $y \in B^{\prime}$.
} 
properties. The upper boundary of $B$ is $b(B)=\{x \in B \mid y \gg x \Rightarrow y \notin$ $B\}$. For any $x \in R_{+}^{L}$, let $\gamma_{B}(x)=\inf \{\lambda>0 \mid x \in \lambda B\}$. When $B$ is a convex set, the function $\gamma_{B}$ is known in convex analysis as the gauge of $B$ (see e.g. Rockafellar (1972)). The following Lemma can be proved by standard arguments.

Lemma 1. Let $B=B^{\prime} \cap R_{+}^{L}$, with $B^{\prime} \subset R_{+}^{L}$ closed, compactly generated, comprehensive and such that $0 \in \operatorname{Int}\left(B^{\prime}\right)$.

(1) $\gamma_{B}: R_{+}^{L} \rightarrow R$ is homogeneous of degree one: for any $k>0$, and $x \in R_{+}^{L}, \gamma_{B}(k x)=k \gamma_{B}(x)$

(2) $\gamma_{B}: R_{+}^{L} \rightarrow R$ is a continuous function

(3) $\gamma_{B}: R_{+}^{L} \rightarrow R$ is increasing: for any $x, y \in R_{+}^{L}, y>>x$ implies $\gamma_{B}(y)>\gamma_{B}(x)$

(4) $B=\left\{x \in R_{+}^{L} \mid \gamma_{B}(x) \leq 1\right\}$, and

(5) $b(B)=\left\{x \in R_{+}^{L} \mid \gamma_{B}(x)=1\right\}$

Letting $g(x)=\gamma_{B}(x)-1, B=\left\{x \in R_{+}^{L} \mid g(x) \leq 0\right\}$.

1.1. Afriat's inequalities. Fix a consumption experiment $\left(x_{k}, B_{k}\right)_{k=1, \ldots n}$. We say that the function $v: X \rightarrow R$ rationalizes the experiment if, for all $k, g_{k}(x) \leq 0$ implies $v(x) \leq v\left(x_{k}\right)$. We say that $x_{k}$ is revealed preferred to $x_{j}, x_{k} R x_{j}$, if $g_{k}\left(x_{j}\right) \leq g_{k}\left(x_{k}\right)=0$. Let $H$ be the transitive closure of the relation $R$. The standard competitive case corresponds to $g_{k}\left(x_{j}\right)=p_{k}\left(x_{j}-x_{k}\right)$, where $p_{k}$ is the price vector. The following Axiom is a variation of the SARP introduced by Varian (1982), in the linear case, to deal with the possibility of indifference.

Definition (GARP): the experiment $\left(x_{k}, B_{k}\right)_{k=1, \ldots n}$ satisfies GARP if, for any $k, j, x_{k} H x_{j}$ implies $g_{j}\left(x_{k}\right) \geq 0$.

It is convenient to express GARP as a condition on the elements of a square matrix. To each consumption experiment $\left(x_{k}, B_{k}\right)_{k=1, \ldots n}$, we associate an $(n \times n)$ matrix $A$ with elements $a_{k j}=g_{k}\left(x_{j}\right)$.

Definition (Cyclical Consistency): a square matrix $A$ of dimension $n$ is cyclically consistent if for every chain $\{k, j, l, \ldots m\} \subset\{1, \ldots n\}$, $a_{k j} \leq 0, a_{j l} \leq 0, \ldots a_{m k} \leq 0$ implies that all terms are zero.

An experiment satisfies GARP if and only if the associated matrix $A$ is cyclically consistent. Suppose $A$ is cyclically consistent, and let $x_{k} H x_{m}$. This means that there are indices $\{j, l, \ldots h\}$ such that $a_{k j} \leq$ $0, a_{j l} \leq 0, \ldots a_{h m} \leq 0$. If $g_{m}\left(x_{k}\right)<0,\{k, j, l, \ldots h, m\}$ would be a chain satisfying the premise in the definition of cyclical consistency. But then $a_{m k}=g_{m}\left(x_{k}\right)=0$ would lead to a contradiction. Thus we must have $g_{m}\left(x_{k}\right) \geq 0$, i.e. GARP holds. In the other direction, let the experiment satisfy GARP, contruct the associated matrix $A$ and take a chain $\{k, j, l, \ldots h, m\}$ satisfying the premise of the definition of cyclical 
consistency. For any two adjacent elements in the chain, say $(j, l)$, by going through the chain we have $x_{l} H x_{j}$. Applying GARP, it must be that $g_{j}\left(x_{l}\right)=a_{j l} \geq 0$, so that $a_{j l}=0$. This is true for any couple of adjacent elements in the chain, i.e. Cyclical Consistency holds.

Lemma 2. If a square matrix A of dimension $n$ is cyclically consistent, there exist numbers $\left(v_{k}, \lambda_{k}\right)_{k=1, \ldots . n}, \lambda_{k}>0$, such that, for all $k, j=$ $1, \ldots n$,

$$
v_{j} \leq v_{k}+\lambda_{k} a_{k j}
$$

Proof: See Fostel, Scarf and Todd (2004), sections 2 and 3.

We are now able to state our generalization of Afriat's Theorem.

Proposition 1. Let $B_{k}=\left\{x \in R_{+}^{L} \mid g_{k}(x) \leq 0\right\}$ with $g_{k}: R_{+}^{L} \rightarrow R$ an increasing, continuous function and $g_{k}\left(x_{k}\right)=0$, for $k=1, \ldots n$. The following conditions are equivalent:

(1) there exists a locally non satiated, continuous utility function $v$ rationalizing the experiment $\left(x_{k}, B_{k}\right)_{k=1, \ldots n}$

(2) the experiment $\left(x_{k}, B_{k}\right)_{k=1, \ldots n}$ satisfies $G A R P$

(3) there exist numbers $\left(v_{k}, \lambda_{k}\right)_{k=1, \ldots n}, \lambda_{k}>0$, such that, for all $k, j=1, \ldots n$

$$
v_{j} \leq v_{k}+\lambda_{k} g_{k}\left(x_{j}\right)
$$

Proof:

$(1) \rightarrow(2)$ : Let $x_{k} H x_{j}$ : there exist indices $(g, \ldots m)$ such that $x_{k} R x_{g} R \ldots R x_{m} R x_{j}$. We want to show that $g_{j}\left(x_{k}\right) \geq 0$. Using the definition of $R, g_{k}\left(x_{g}\right) \leq 0, \ldots, g_{m}\left(x_{j}\right) \leq 0$. If $v$ rationalizes the experiment, we must have $v\left(x_{k}\right) \geq v\left(x_{g}\right) \geq \ldots v\left(x_{m}\right) \geq v\left(x_{j}\right)$, implying $v\left(x_{k}\right) \geq v\left(x_{j}\right)$. If $g_{j}\left(x_{k}\right)<0$, by the local non satiation of $v$ and the continuity of $g_{j}$ we could find $x \in X$ such that $g_{j}(x)<0$ and $v(x)>v\left(x_{k}\right) \geq v\left(x_{j}\right)$, contradicting the fact that $v$ rationalizes the experiment.

$(2) \rightarrow(3)$ : construct the matrix $A$ associated with the experiment. By (2), $A$ is cyclically consistent. Then use Lemma 2 .

$(3) \rightarrow(1)$ : Let $v(x)=\min _{k}\left\{v_{k}+\lambda_{k} g_{k}(x)\right\}$. The function $v$ is increasing and continuous on $R_{+}^{L}$. To show that it rationalizes the data, notice first that, for all $j, v\left(x_{j}\right)=\min _{k}\left\{v_{k}+\lambda_{k} g_{k}\left(x_{j}\right)\right\}=v_{j}$, using the Afriat's inequalities in (3) and the fact that $g_{j}\left(x_{j}\right)=0$. Then, if we consider $x$ such that $g_{j}(x) \leq 0$ we have $v(x) \leq v_{j}+\lambda_{j} g_{j}(x) \leq v_{j}=v\left(x_{j}\right)$. 
In the competitive setting originally considered by Afriat, the inequalities in (3) take the form:

$$
v_{j} \leq v_{k}+\lambda_{k} p_{k}\left(x_{j}-x_{k}\right)
$$

This corresponds to choosing $a_{k j}=p_{k}\left(x_{j}-x_{k}\right)$ in Lemma 2, as explicitly done in Fostel et al. (2004). As it is clear from the discussion preceding Lemma 2, if the experiment satisfies GARP, the existence of the numbers $\left(v_{k}, \lambda_{k}\right)_{k=1, \ldots n}$ follows for any matrix $A$ having the property that $a_{k j} \leq 0$ if $x_{k}$ is revealed preferred to $x_{j}$. Our contribution is to notice that, in the general setting that we consider, one can choose $a_{k j}=g_{k}\left(x_{j}\right)$, and still obtain, in the last step of the proof, an explicit utility function defined on the entire consumption set.

1.2. Testing concavity. Consider now consumption experiments in which $B_{k}=\left\{x \in R_{+}^{L} \mid f_{k}(x) \leq 0\right\}$ with $f_{k}\left(x_{k}\right)=0$ where $f_{k}: R_{+}^{L} \rightarrow R$ is not only increasing and continuous, but also quasi - convex and differentiable at $x_{k}$, for all $k=1, \ldots n$. In this case, the gradient $\nabla f_{k}\left(x_{k}\right)$ identifies the unique supporting hyperplane of $B_{k}$ at $x_{k}$.

For each $\left(x_{k}, B_{k}\right)$, let $C_{k}=\left\{x \in R_{+}^{L} \mid \nabla f_{k}\left(x_{k}\right)\left(x-x_{k}\right) \leq 0\right\}$. If we let $g_{k}(x)=\nabla f_{k}\left(x_{k}\right)\left(x-x_{k}\right)$, we can apply our definitions of $R, H$ and GARP to the 'linearized' experiment $\left(x_{k}, C_{k}\right)_{k=1, \ldots n}$.

Proposition 2. Let $B_{k}=\left\{x \in R_{+}^{L} \mid f_{k}(x) \leq 0\right\}$ with $f_{k}\left(x_{k}\right)=0$ where $f_{k}: R_{+}^{L} \rightarrow R$ is increasing, continuous, quasi-convex and differentiable at $x_{k}$, for $k=1, \ldots n$. The following conditions are equivalent:

1') there exists a locally non satiated, continuous and concave utility function $v$ rationalizing the experiment $\left(x_{k}, B_{k}\right)_{k=1, \ldots n}$

2 ') the 'linearized' experiment $\left(x_{k}, C_{k}\right)_{k=1, \ldots n}$ associated with $\left(x_{k}, B_{k}\right)_{k=1, \ldots n}$ satisfies GARP

3') there exist positive numbers $\left(v_{k}, \lambda_{k}\right)_{k=1, \ldots n}, \lambda_{k}>0$, such that, for all $k, j=1, \ldots n$,

$$
v_{j} \leq v_{k}+\lambda_{k} \nabla f_{k}\left(x_{k}\right)\left(x_{j}-x_{k}\right)
$$

Proof:

$\left(1^{\prime}\right) \rightarrow\left(2^{\prime}\right)$ : Define $R$ and $H$ in terms of the linearized experiment $\left(x_{k}, C_{k}\right)_{k=1, \ldots n}$. Let $x_{k} H x_{j}$ : there exists indices $(g, \ldots m)$ such that $x_{k} R x_{g} R \ldots R x_{m} R x_{j}$. From the definition of $R, \nabla f_{k}\left(x_{k}\right)\left(x_{g}-x_{k}\right) \leq 0$, $\ldots, \nabla f_{m}\left(x_{m}\right)\left(x_{j}-x_{m}\right) \leq 0$.

If $v: R_{+}^{L} \rightarrow R$ is a locally non satiated, continuous, concave utility function rationalizing the (non linearized ) experiment $\left(x_{k}, B_{k}\right)_{k=1, \ldots n}$, 
each observation $x_{k}$ is a maximizer of $v$ on the convex set $B_{k}=\{x \in$ $\left.R_{+}^{L} \mid f_{k}(x) \leq 0\right\}$ and we have:

$$
v(x) \leq v\left(x_{k}\right)+\alpha_{k} \nabla f_{k}\left(x_{k}\right)\left(x-x_{k}\right)
$$

with $\alpha_{k}>0$ (using local non satiation). If $x_{k} H x_{j}$ we then have $v\left(x_{k}\right) \geq$ $v\left(x_{g}\right), \geq \ldots v\left(x_{m}\right) \geq v\left(x_{j}\right)$, and thus $v\left(x_{k}\right) \geq v\left(x_{j}\right)$. We need to show that $\nabla f_{j}\left(x_{j}\right)\left(x_{k}-x_{j}\right) \geq 0$. If this was not the case, by local non satiation we could find $x$ such that $\nabla f_{j}\left(x_{j}\right)\left(x-x_{j}\right)<0$ and $v(x)>$ $v\left(x_{j}\right)$, contradicting the fact that $v$ is a concave function rationalizing the experiment.

$\left(2^{\prime}\right) \rightarrow\left(3^{\prime}\right)$ : construct the matrix $A$ associated with the linearized experiment $\left(x_{k}, C_{k}\right)_{k=1, \ldots n}$. By $\left(2^{\prime}\right), A$ is cyclically consistent. Then use Lemma 2.

$\left(3^{\prime}\right) \rightarrow\left(1^{\prime}\right)$ : Let $v(x)=\min _{k}\left\{v_{k}+\lambda_{k} \nabla f_{k}\left(x_{k}\right)\left(x-x_{k}\right)\right\}$. The function $v$ is increasing and continuous on $R_{+}^{L}$. It is also concave, as the minimum of finitely many linear functions. To show that it rationalizes the data, notice first that, for all $j, v\left(x_{j}\right)=v_{j}$, using the Afriat's inequalities in $\left(3^{\prime}\right)$. Then, if we consider $x$ such that $f_{j}(x) \leq 0$ we have $v(x) \leq v_{j}+\lambda_{j} \nabla f_{j}\left(x_{j}\right)\left(x-x_{j}\right) \leq v_{j}=v\left(x_{j}\right)$, where the first inequality follows from the definition of $v$, the second from the quasi - convexity of $f_{j}, f_{j}(x) \leq 0$ and the fact that, in the experiment, $f_{j}\left(x_{j}\right)=0$.

If the experiment satisfies the premise of Proposition 2, we may consider two sets of testable conditions: those in $2^{\prime}$ ), and the 'nonlinearized' ones, 2). If the experiment satisfies 2) but not $2^{\prime}$ ) a rationalization is possible, but preferences cannot be represented by a concave utility function.

1.3. Comparison with previous results. Matzkin (1991) explicitly deals with nonlinear choice sets. She proves that the existence of a strictly concave rationalization is equivalent to the strong axiom of revealed preference when every choice $(x, B)$ is either co-convex (i.e., $B$ as in Lemma 1 and $B^{c} \cap R_{+}^{L}$ convex) or supportable (i.e., $B$ as in Lemma 1 , convex and supported by a unique hyperplane at $x$ ). Our main result, Proposition 1, does not require any additional assumption besides those in Lemma 1. On the other hand, the utility function that we construct from Afriat's inequalities need not be concave.

The first two statements of Proposition 2 above are similar to Matzkin's Theorem 2. Our approach, which exploits the representation of budget sets by means of the $g$ functions, allows us to derive an exact analog of Afriat's inequalities, leading to a much easier construction of the concave utility function rationalizing the data. 
To complete the comparison, in the co-convex case our construction immediately yields a concave rationalization of the data. If $B$ is co-convex, the function $\gamma_{B}: R_{+}^{L} \rightarrow R$ is concave. Then, if we let $g(x)=\gamma_{B}(x)-1$ for all $x \in R_{+}^{L}$, the rationalization obtained in (3) of Proposition 1 is concave as a minimum of concave functions. This is essentially Matzkin's Theorem 1.

Independently of Matzkin (1991), Chavas and Cox (1993) allow the consumer to face finitely many nonlinear budget constraints. They impose restrictions in order to convert the consumer's underlying optimization problem into a saddle-point problem. They do not formulate any axiom of revealed preference but express necessary and sufficient conditions for rationalization as explicit generalized Afriat's inequalities. Our Proposition 1 is more general: the budget sets considered above can clearly accommodate multiple constraints, but our result does not require any convexity assumption, like Chavas and Cox (1993)'s assumption 2. At the same time our proof is much more direct.

\section{Uniqueness and Approximation}

In the theory of revealed preferences, besides the question of the existence of a rationalization, it is interesting to investigate the issue of uniqueness: can we fully identify the preferences of an individual by observing his behavior? The question has to be made precise. We cannot hope to identify preferences over a non finite choice set from observation of finitely many choices. Also, if we allow the individual to be indifferent among elements of a given set of alternatives, we must be able to observe all of his preferred choices at that set of alternative, not just one. The spirit of the exercise is thus quite different from the "finite observation' methodology we followed until now. Nevertheless the question has been investigated for the case of the classical competitive consumer, facing linear budgets (see Mas Colell (1977), (1978)), and, not surprisingly, in our much larger class of possible budgets, things are simpler. In this section, we take the strictly positive orthant $X=R_{++}^{L}$ as our consumption set.

The main idea is that if we restrict attention to monotonic preferences, we can always simulate a choice between any pair of alternatives $y, z \in X$ by proposing to the individual the budget

$$
B_{y, z}=\{x \in X \mid x \leq y\} \cup\{x \in X \mid x \leq z\}
$$

To state the observation more precisely, let $\mathbb{B}$ be the set of all budgets obtained as the intersection $B^{\prime} \cap X$ with $B^{\prime} \subset R^{L}$ closed, compactly generated, comprehensive and such that $0 \in \operatorname{Int}\left(B^{\prime}\right)$. Let $h: \mathbb{B} \rightarrow X$ be the individual choice correspondence, with $h(B) \subset B, h(B) \neq \emptyset$ for all $B \in \mathbb{B}$. 
For a given individual choice correspondence $h$, we say that $x$ is revealed preferred to $y$, and we write $x R(h) y$, iff there exists $B \in \mathbb{B}$ such that $x, y \in B$ and $x \in h(B)$. We may also define the relation $P(h)$ as $x P(h) y$ iff there exists $B \in \mathbb{B}$ such that $x, y \in B, x \in h(B)$, $y \notin h(B)$. The weak axiom of revealed preference can then be stated as follows

Definition (WARP): the individual choice correspondence satisfies WARP if $[x R(h) y] \Longrightarrow[\neg y P(h) x]$.

We also introduce an additional condition which is natural, given our restriction to monotonic preferences

Definition (Monotonic choice): the individual choice correspondence is monotonic if, for all $B \in \mathbb{B},[x \in h(B), y>x] \Longrightarrow[y \notin B]$.

A preference relation $\succcurlyeq$ is a reflexive, complete, transitive binary relation on $X$. $\succcurlyeq$ is monotonic if $x>>y$ implies $x \succ y$, i.e. $x \succcurlyeq y$ and $\neg y \succcurlyeq x$. $\succcurlyeq$ is upper semicontinuous if $\forall x \in X$ the set $\succcurlyeq(x)=$ $\{y \in X \mid y \succcurlyeq x\}$ is closed in $X$. We say that a preference relation $\succcurlyeq$ generates the individual choice correspondence $h$ on $\mathbb{B}$ if, for all $B \in \mathbb{B}$, $h(B)=\{x \in B \mid[y \in B] \Longrightarrow x \succcurlyeq y\}$. This is stronger than simply requiring that $\succcurlyeq$ rationalizes $h$, which corresponds to the inclusion $\subset$.

The following Proposition should be compared with Theorem $2^{\prime}$ of Mas-Colell (1977). In our setting, given the large class of admissible budget sets, both the statement and the proof are simpler. Our result is actually closer to Arrow (1959), which requires that the class of admissible budgets contains all finite sets of up to three alternatives.

Proposition 3. If the individual choice correspondence $h$ is monotonic and satisfies WARP, $R(h)$ is the unique preference which generates it.

Proof:

$R(h)$ is complete because for any $y, z \in X, B_{y, z} \in \mathbb{B}$.

To show that $R(h)$ is transitive, let $x R(h) y, y R(h) z$, i.e., there exists $B \in \mathbb{B}$ such that $x, y \in B$ and $x \in h(B)$, and $B^{\prime} \in \mathbb{B}$ such that $y, z \in B^{\prime}$ and $y \in h\left(B^{\prime}\right)$. Take now $B_{x, y, z} \in \mathbb{B}$, defined in the obvious way. We have to show that $x \in h\left(B_{x, y, z}\right)$. Because $h$ is monotonic, at least one of the three elements $x, y, z$ must belong to $h\left(B_{x, y, z}\right)$. If it is $x$, we are done. If on the other hand $y \in h\left(B_{x, y, z}\right)$, then by WARP we should also have $x \in h\left(B_{x, y, z}\right)$, and similarly if $z \in h\left(B_{x, y, z}\right)$.

$R(h)$ generates $h$ on $\mathbb{B}$. We have to show that for all $B \in \mathbb{B}, h(B)=$ $\{x \in B \mid[y \in B] \Longrightarrow x R(h) y\}$. Let $x$ be an element of the set on the right hand side. If $x \notin h(B)$, then there exists $y \in B, x \neq y$, $y \in h(B)$, i.e. $y P(h) x$, contradicting WARP. In the other direction, take $x \in h(B)$. If $y \in B$, then by definition of $R(h) x R(h) y$, i.e. $x$ belongs to the right hand side. 
To show uniqueness, assume there exists $\succcurlyeq$ generating $h$, i.e. for any $B \in \mathbb{B} h(B)=\{x \in B \mid[y \in B] \Longrightarrow x \succcurlyeq y\}$. Clearly, for any couple of bundles $\left(z, z^{\prime}\right)$, if $z R(h) z^{\prime}$ then $z \succcurlyeq z^{\prime}$. In the other direction, if $z \succcurlyeq z^{\prime}$, by monotonicity it must be that $z \in\left\{x \in B_{z, z^{\prime}} \mid[y \in\right.$ $\left.\left.B_{z, z^{\prime}}\right] \Longrightarrow x \succcurlyeq y\right\}=h\left(B_{z, z^{\prime}}\right)$, implying $z R(h) z^{\prime}$.

The uniqueness result in this proposition depends on the fact that we know the full choice correspondence: in the very last step of the proof we used the inclusion $\left\{x \in B_{z, z^{\prime}} \mid\left[y \in B_{z, z^{\prime}}\right] \Longrightarrow x \succcurlyeq y\right\} \subset h\left(B_{z, z^{\prime}}\right)$. It would not be enough to require that the observed choice $h\left(B_{z, z^{\prime}}\right)$ be an element of the set of preferred bundles. Indeed, an individual indifferent between $z$ and $z^{\prime}$ could always choose $z^{\prime}$ when confronted with $B_{z, z^{\prime}}$ and there would be no hope to fully identify her preferences.

Even under this stronger requirement, it is interesting to investigate to what extent one can reconcile this approach with the one of the previous section, in which only finitely many budgets are included in each experiment. This is the question of approximation, first raised, for the case of the competitive consumer, by Mas-Colell (1978).

Following his approach, we consider a sequence of finite experiments which becomes richer and richer at every step, and which 'tends' to the whole of $\mathbb{B}$. Let $\mathcal{K}(X)$ be the set of all non empty compact subsets of $X$. Endowed with the Hausdorff metric, $\mathcal{K}(X)$ is a separable metric space (See e.g. Aliprantis and Border (2000) chapter 3 for definitions and results, especially 3.76 and 3.77 , p. 115$). \mathbb{B} \subset \mathcal{K}(X)$ inherits these properties. Let $C_{n}$ be a collection of $n$ elements of $\mathbb{B}$, and consider an increasing sequence of collection of sets $C_{1} \subset C_{2} \subset \ldots C_{n-1} \subset C_{n} \ldots$ such that their union is dense in $\mathbb{B}: \overline{\cup_{n} C_{n}}=\mathbb{B}$. For each collection $C_{n}$, let $\mathcal{R}_{n}$ be the set of upper semicontinuous, monotonic preferences which generate $h$ on $C_{n}$. We obtain a decreasing sequence .., $\mathcal{R}_{n} \supset \mathcal{R}_{n+1}, \ldots$.

Proposition 4. If the individual choice correspondence $h: \mathbb{B} \rightarrow X$ has closed values, is monotonic and upper hemi-continuous, and satisfies $W A R P$, then $\cap_{n} \mathcal{R}_{n}=\{R(h)\}$.

Proof:

We first show that $R(h) \in \cap_{n} \mathcal{R}_{n}$.

As shown in the proof of Proposition $3, R(h)$ generates $h$ on $\mathbb{B}$. $R(h)$ is monotonic. Let $z>>y$. We have to show that $z R(h) y$ and $\neg y R(h) z$. Take $B_{z}=\{x \in X \mid x \leq z\}$. Clearly, $y, z \in B_{z}$. If $z \notin h\left(B_{z}\right), \exists x \leq z x \in h\left(B_{z}\right)$, contradicting the monotonicity of $h$; thus $z \in h\left(B_{z}\right)$ and $z R(h) y$. If we also had $y R(h) z$, we would have that for all $B$ with $(z, y) \in B$, if $z \in h(B)$ then $y \in h(B)$. Again, for $B=B_{z}$ this would contradict the monotonicity of $h$. 
$R(h)$ is upper semicontinuous. We have to show that, $\forall x \in X$, the set $R(h)(x)=\{y \in X \mid y R(h) x\}$ is closed. Take a sequence $\left(y_{n}\right)_{n \geq 1}$ converging to $y$, such that $\forall n y_{n} R(h) x$. That is, $\forall n \exists B_{n} \in \mathbb{B}$ such that $y_{n}, x \in B_{n}$ and $y_{n} \in h\left(B_{n}\right)$. If we consider $B_{y_{n}, x}$, by monotonicity of $h$ and WARP $y_{n} \in h\left(B_{y_{n}, x}\right), \forall n$. The sequence of sets $\left(B_{y_{n}, x}\right)_{n \geq 1}$ converges in the Hausdorff metric to $B_{y, x}$, and, by u.h.c. of $h, y \in$ $h\left(B_{y, x}\right)$.

It remains to show that there is no other element in $\cap_{n} \mathcal{R}_{n}$.

Suppose there exists $\succcurlyeq \in \cap_{n} \mathcal{R}_{n}, \succcurlyeq \neq R(h)$. Then we can find $x, y \in X$ such that $x \succcurlyeq y$ and $x \in R(h)(y)^{c}$. By u.s.c. of $R(h), R(h)(y)^{c}$ is an open set. By monotonicity of $\succcurlyeq$, we can take $x, y \in X$ such that $x \succ y$ and $x \in R(h)(y)^{c}$.

Using again the u.s.c. and monotonicity of both $\succcurlyeq$ and $R(h)$ we can actually claim more. There exists $\eta>0$ such that, if we define

$$
\begin{aligned}
& x_{\alpha}=x+(1-\alpha) \eta \mathbf{1} \\
& y_{\beta}=y+(1-\beta) \eta \mathbf{1}
\end{aligned}
$$

then, for all $\alpha \in[0,1]$ and all $\beta \in[0,1]$,

$$
\begin{gathered}
y_{\beta} \notin \succcurlyeq\left(x_{\alpha}\right) \\
x_{\alpha} \notin R(h)\left(y_{\beta}\right) .
\end{gathered}
$$

Fix now $\alpha=\beta=\frac{1}{2}$. To simplify notation, let us denote the 'corner' budget $B_{x_{\frac{1}{2}}, y_{\frac{1}{2}}}$ simply by $\hat{B}$. For any $\epsilon>0$, consider the open set around $\hat{B}$ defined by

$$
\mathcal{O}^{\epsilon}=\{F \in \mathbb{B} \mid \mathcal{H}(F, \hat{B})<\epsilon\}
$$

where $\mathcal{H}$ is the Hausdorff distance. We claim that, for any $\epsilon<\frac{\eta}{3}$, if $F \in \mathcal{O}^{\epsilon}$, then $x \in F$ and $y \in F$. Indeed, if e.g. $x$ did not belong to $F$, then, by comprehensiveness of $F$, none of the points $y \geq x$ would be in $F$. But the closest point $z$ to $x_{\frac{1}{2}}$ for which it is not the case that $z \geq x$ is at distance at least $\frac{\eta}{2}$ from $x_{\frac{1}{2}}$. Clearly, $\epsilon<\frac{\eta}{3}<\frac{\eta}{2}$ and the argument above contradicts the fact that $F \in \mathcal{O}^{\epsilon}$.

Observe now that, again for $\epsilon<\frac{\eta}{3}$, by a similar argument, if $F \in \mathcal{O}^{\epsilon}$, then $F \subset B_{x_{0}, y_{0}}$. Then, by monotonicity of $R(h)$, if $b \in F$ then either $x_{0} R(h) b$ or $y_{0} R(h) b$. If $x_{0} R(h) b$, then it cannot be that $b R(h) y$, because this would imply $x_{0} R(h) y$, which is false by construction. Remember that $y \in F$, so that, if we define $V=\left[R(h)(y) \cap B_{y_{0}}\right]$, we must have $h(F) \subset V$.

Using now the fact that $\cup_{n} C_{n}$ is dense in $\mathbb{B}$, there exist $n$ and $B \in$ $C_{n}$ such that $B \in \mathcal{O}^{\epsilon}$. Then, by our argument above we can find $b \in h(B) \subset V$. From the fact that $x \in B$, and that $\succcurlyeq$ generates 
$h$ on $C_{n}$, this implies $b \succcurlyeq x$. Finally, from $b \in V, y_{0} \geq b$, and by monotonicity and u.s.c. of $\succcurlyeq, y_{0} \succcurlyeq b$. We therefore obtain $y_{0} \succcurlyeq x$, a contradiction.

\section{Applichtion: Market Games}

Given a standard exchange economy, a market mechanism consists of a set of strategies (bids, offers, etc.) for every agent and an outcome function that maps strategy profiles into allocations of commodities. Fixing the strategies of the others, each player generates a set of consumption bundles as she varies her strategy. The individual problem can thus be expressed as the maximization of the player's preferences over a 'budget set'. Typically, the strategy chosen by a player has some influence on the 'terms of trade', and we should not expect the frontier of the budget set to be linear. Strategic market interactions are thus a natural setting for the application of our generalization of Afriat's theory. We show that, for a broad class of market mechanisms axiomatized by Dubey and Sahi (2003), individual 'budget sets' are exactly of the form covered by our Lemma 1 . As an immediate corollary of Proposition 1 we obtain a set of testable restrictions which are necessary and sufficient to interpret the observed choices as Nash equilibrium outcomes.

Consider an economy composed by a finite group of individuals $i \in$ $\{1, \cdots, I\}$. Commodities are $l \in\{1, \cdots L\}$. The initial endowment of commodities of inidividual $i$ is $e^{i} \in R_{++}^{L}$, and we denote her final consumption by $x^{i} \in R_{+}^{L}$. Traders bring goods to the market, and the market generates a vector of prices and an allocation of goods. Each good may be brought to one or more markets, and an action for an individual is a vector $a^{i} \in R_{+}^{S}$. For example if there are two commodities and each can be brought to two markets, $S=4$. We can obtain the total amount of the $L$ commodities needed to carry out action $a^{i}$ by means of a 'summing-up' matrix $M$ of dimension $L \times S$ : $M a^{i} \in R_{+}^{L}$. The market mechanism specifies a price vector $p \in P=$ $R_{++}^{L}$ and an allocation $\left(x^{i} \in R_{+}^{L}\right)_{i \in I}$ as a result of the individual actions. We do not require the mechanism to be defined if the total quantity of any good brought to any market is zero. Let $\mathbb{A}=\left\{a \in R_{+}^{S I} \mid \sum_{i} a^{i}>>\right.$ $0\}$. A market mechanism is then a collection of functions $p: \mathbb{A} \rightarrow P$, $r^{i}: \mathbb{A} \rightarrow R_{+}^{L}$ such that

Exact Feasibility: For all $a \in \mathbb{A}, \sum_{i} r^{i}(a)=\sum_{i} M a^{i}$

Budget Balance: For all $a \in \mathbb{A}$, and all $i \in I, p(a) r^{i}(a)=p(a) M a^{i}$ 
Dubey and Sahi show that if a mechanism satisfies natural properties of Aggregation, Invariance and Price Mediation, one can equivalently represent it by means of price and allocation functions, $p: R_{++}^{S} \rightarrow P$ and $z: R_{+}^{S} \times P \rightarrow R_{+}^{L}$. Prices only depend on the aggregate quantity $\bar{a}=\sum_{i} a^{i}$, and $r^{i}(a)=z\left(a^{i}, p(\bar{a})\right)$.

The mechanism, as defined by the two functions $(p, z)$, is anonymous: the action set is the same for all individuals, $R_{+}^{S}$. When applying a mechanisms to a particular economy, we may impose individual feasibility: the total quantity of a commodity delivered by an individual cannot exceed her initial endowment. The action set of individual $i$ is then $A^{i}=\left\{a^{i} \in R_{+}^{S} \mid M a^{i} \leq e^{i}\right\}$. From now on, let us then define a mechanism for our economy as $\Gamma=\left\{\left(A^{i}\right)_{i \in I},(p, z)\right\}$. The subset of individually feasible actions over which the maps $(p, z)$ are defined is $A=$ $\left\{a \in \times A^{i} \mid \sum_{i} a^{i}>>0\right\}$. At a profile of choices $a \in A$, the final bundle obtained by individual $i$ is $x^{i}\left(a^{i}, a^{-i}\right)=e^{i}-M a^{i}+z\left(a^{i}, p\left(a^{i}+\sum_{j \neq i} a^{j}\right)\right)$. For given choices of the other individuals with $\sum_{j \neq i} a^{j}>>0$, the set of attainable consumption bundles of individual $i$ is:

$$
B^{i}\left(a^{-i}\right)=\left\{x^{i} \in R_{+}^{L} \mid \exists a^{i} \in A^{i} \text { s.t. } x^{i} \leq x^{i}\left(a^{i}, a^{-i}\right)\right\}
$$

By feasibility, the set $B^{i}\left(a^{-i}\right)$ is bounded. By budget balance, the fact that prices are strictly positive, and that $e^{i}>>0$, it contains 0 in its interior. If the function $x^{i}\left(\cdot, a^{-i}\right): A^{i} \rightarrow R_{+}^{L}$ is continuous, the set is closed. As in Lemma 1 one could define continuous increasing functions $g^{i}\left(\cdot ; a^{-i}\right): R_{+}^{L} \rightarrow R$ such that

$$
B^{i}\left(a^{-i}\right)=\left\{x^{i} \in R_{+}^{L} \mid g^{i}\left(x^{i} ; a^{-i}\right) \leq 0\right\}
$$

A market mechanism $\Gamma=\left\{I,\left(A^{i}\right)_{i \in I},(p, z)\right\}$, and a collection of utility functions, $v^{i}: R_{+}^{L} \rightarrow R, i \in I$ define a market game $\left\{I,\left(v^{i}\right)_{i \in I}, \Gamma\right\}$ in which the strategy set of individual $i$ is $A^{i}$, and her utility ${ }^{3}$ at the profile $a \in \times_{i} A^{i}$ is $v^{i}\left[x^{i}\left(a^{i}, a^{-i}\right)\right]$. An active profile of strategies is $a \in \times_{i} A^{i}$ with $\sum_{j \neq i} a^{j}>>0$ for all $i \in I$. An active Nash equilibrium of $\left\{I,\left(v^{i}\right)_{i \in I}, \Gamma\right\}$ is an active profile such that, for all $i \in I$, and for all $b \in A^{i}$,

$$
v^{i}\left[x^{i}\left(b, a^{-i}\right)\right] \leq v^{i}\left[x^{i}\left(a^{i}, a^{-i}\right)\right]
$$

Equivalently, it is an active profile of strategies $a \in \times_{i} A^{i}$ such that, for all $i \in I$, and for all $x^{i} \in B^{i}\left(a^{-i}\right), v^{i}\left[x^{i}\right] \leq v^{i}\left[x^{i}(a)\right]$.

\footnotetext{
${ }^{3}$ To define utilities for the market game, we need to extend the market mechanism to the whole of $\times_{i} A^{i}$. This has been done in the literature for different subclasses of mechanisms, at the cost of introducing discontinuities (see e.g. Shapley (1976)). In our setting, we can always avoid the discontinuity by retaining only the observations corresponding to active profiles, as done here.
} 
3.1. Rationalization. An experiment is a collection of observations of strategies chosen by a fixed set of individuals. We allow the observations to come from different market mechanisms. An experiment is thus a collection $\left(a_{k}, \Gamma_{k}\right)_{k=1, \ldots n}$ where all the market mechanisms have the same set of individuals $I$ and, for each $k, a_{k} \in A_{k}$ is an active profile.

We say that the collection of utility functions $\left(v^{i}: R_{+}^{L} \rightarrow R\right)_{i \in I}$ rationalizes the experiment $\left(a_{k}, \Gamma_{k}\right)_{k=1, \ldots n}$ if, for all $k, a_{k}$ is a Nash equilibrium of the market game $\left\{I,\left(v^{i}\right)_{i \in I}, \Gamma_{k}\right\}$.

Given an experiment $\left(a_{k}, \Gamma_{k}\right)_{k=1, \ldots n}$, we can construct data on the trades of individuals and on their budget sets:

$$
\begin{gathered}
x_{k}^{i}=e_{k}^{i}-M_{k} a_{k}^{i}+z_{k}\left(a_{k}^{i}, p_{k}\left(\bar{a}_{k}\right)\right) \\
B_{k}^{i}=\left\{x^{i} \in R_{+}^{L} \mid \exists a^{i} \in A_{k}^{i} s \cdot t \cdot x^{i} \leq e_{k}^{i}-M_{k} a_{k}^{i}+z_{k}\left(a^{i}, p_{k}\left(a^{i}+\sum_{j \neq i} a_{k}^{j}\right)\right)\right\} \\
=\left\{x^{i} \in R^{L} \mid g_{k}^{i}\left(x^{i}\right) \leq 0\right\} .
\end{gathered}
$$

The expression of $B_{k}^{i}$ in terms of the function $g_{k}^{i}$ introduces an element of arbitrariness, but the set $B_{k}^{i}$ is fully determined by observable entities.

With this notation, $a_{k}$ is a Nash equilibrium of the market game $\left\{I,\left(v^{i}\right)_{i \in I}, \Gamma_{k}\right\}$ if and only if for each individual $i \in I, x \in B_{k}^{i}$ implies $v^{i}[x] \leq v_{i}\left[x_{k}^{i}\right]$.

For a given experiment $\left(a_{k}, \Gamma_{k}\right)_{k=1, \ldots n}$, we say that $x_{k}^{i}$ is revealed preferred by $i$ to $x_{j}^{i}, x_{k}^{i} R^{i} x_{j}^{i}$, if $g_{k}^{i}\left(x_{j}^{i}\right) \leq g_{k}^{i}\left(x_{k}^{i}\right)=0$. Let $H^{i}$ be the transitive closure of the relation $R^{i}$.

The experiment $\left(a_{k}, \Gamma_{k}\right)_{k=1, \ldots n}$ satisfies GARP if, for all $i \in I$, and any $k, j, x_{k}^{i} H^{i} x_{j}^{i}$ implies $g_{j}^{i}\left(x_{k}^{i}\right) \geq 0$.

Proposition 5. The following conditions are equivalent:

(1) there exists a collection of locally non satiated, continuous utility functions $\left(v^{i}\right)_{i \in I}$ rationalizing the experiment $\left(a_{k}, \Gamma_{k}\right)_{k=1, \ldots n}$

(2) the experiment $\left(a_{k}, \Gamma_{k}\right)_{k=1, \ldots n}$ satisfies $G A R P$

(3) there exist numbers $\left(\left(v_{k}^{i}, \lambda_{k}^{i}\right)_{k=1, \ldots n}\right)_{i \in I}, \lambda_{k}^{i}>0$, such that, for all $i \in I$ and all $k, j=1, \ldots n$,

$$
v_{j}^{i} \leq v_{k}^{i}+\lambda_{k}^{i} g_{k}^{i}\left(x_{j}^{i}\right)
$$

This characterization obviously relies on the availability of individual consumption data (as opposed to aggregate ones). On the other hand, we just require the observation of the effective choices of the players as the rules of the game and/or the initial endowments vary. Our result thus differs significantly from those obtained by Sprumont 
(2000) for abstract interactive decision problems, which require the observation of a full joint choice function (i.e., the players' behavior for every conceivable subset of possible strategic choices).

3.2. Testing market power. If the price generated by the market mechanism is not sensitive to changes in the strategy of a individual $i$, Budget Balance implies that the individual is only able to move his net trades, $z\left(a^{i}, p(\bar{a})\right)-M a^{i}=x\left(a^{i}, a^{-i}\right)-e^{i}$ in the linear space orthogonal to $p(\bar{a})$. A price taking consumer will choose consumption to maximize his utility on the budget

$$
C^{i}\left(a^{-i}\right)=\left\{x^{i} \in R_{+}^{L} \mid p(\bar{a})\left(x^{i}-e^{i}\right) \leq 0\right\}
$$

In an experiment $\left(a_{k}, \Gamma_{k}\right)_{k=1, \ldots n}$, we can construct competitive budget sets:

$$
\begin{aligned}
C_{k}^{i} & =\left\{x^{i} \in R_{+}^{L} \mid p_{k}\left(\bar{a}_{k}\right)\left(x^{i}-e_{k}^{i}\right) \leq 0\right\} \\
& =\left\{x^{i} \in R_{+}^{L} \mid f_{k}^{i}\left(x^{i}\right) \leq 0\right\} .
\end{aligned}
$$

with $f_{k}^{i}(x)=p_{k}\left(\bar{a}_{k}\right)\left(x-e_{k}^{i}\right)$, and define GARP in terms of these budgets. If an individual satisfies GARP in terms of the non linear budgets, i.e. 2) of Proposition 4, but fails GARP in terms of the competitive budgets $\left(C^{i}\right)_{k=1, \ldots n}$, we may take this as evidence of a rational individual who perceives his market power. 


\section{REFERENCES}

[1] Afriat, S. (1967), "The construction of a Utility Function from Demand Data", International Economic Review 8, 67-77.

[2] Aliprantis, R. and Border K. (1999), Infinite Dimensional Analysis: a Hitchhiker's Guide, Springer: Berlin, Germany.

[3] Arrow, K. (1959), "Rational Choice Functions and Orderings" , Econometrica $26,121-127$.

[4] Chavas, J.-P. and T. Cox (1993), "On Generalized Revealed Preference Analysis", Quarterly Journal of Economics 108, 493-506.

[5] Diewert, W. (1973), "Afriat and Revealed Preference Theory", The Review of Economic Studies 40, 419-425.

[6] Dubey, P. and S. Sahi (2003), "Price-mediated Trade with Quantity Signals: an Axiomatic Approach", Journal of Mathematical Economics 39, 377-389.

[7] Fostel, A., H. Scarf and M. Todd (2004), "Two New Proofs of Afriat's Theorem", Economic Theory 24, 211-219.

[8] Houthakker, H. (1950), "Revealed Preference and the Utility Function", Economica NS 17, 159 -174.

[9] Mas Colell, A. (1977), "The Recoverability of Consumers Preferences from Market Demand Behavior", Econometrica 45, 1409-1430.

[10] Mas Colell, A. (1978), "On Revealed Preference Analysis", The Review of Economic Studies 45, 121-131.

[11] Matzkin, R. (1991), "Axioms of Revealed Preferences for Nonlinear Choice Sets", Econometrica 59, 1779-1786.

[12] Richter, M. (1966), "Revealed Preference Theory", Econometrica 34, 635645 .

[13] Rockafellar, T. (1972), Convex Analysis, Princeton University Press.

[14] Samuelson, P. (1938), "A Note on the Pure Theory of Consumer's Behavior", Economica NS 5, 61-71.

[15] Shapley, L. (1976), "Non - Cooperative General Exchange", in Liu (ed) Theory and Measurement of Economic Externalities, Academic Press: New York.

[16] Shapley, L. and M. Shubik, (1977), "Trade Using a Commodity as a Means of Payment", Journal of Political Economy 85, 937-968.

[17] Sprumont, Y. (2000), "On the Testable Implications of Collective Choice Theories", Journal of Economic Theory 93, 205-232.

[18] Varian, H. (1982), "The Nonparametric Approach to Demand Analysis", Econometrica 50, 945-973.

Françoise Forges: CEREMAde, Université Paris - Dauphine, France

E-mail address: francoise.forges@dauphine.fr

Enrico Minelli: Dipartimento di Scienze Economiche, Università di BRESCIA, ITALIA

E-mail address: minelli@eco.unibs.it 


\section{CESifo Working Paper Series}

(for full list see www.cesifo-group.de)

1641 Stefan Bach, Giacomo Corneo and Viktor Steiner, Top Incomes and Top Taxes in Germany, January 2006

1642 Johann K. Brunner and Susanne Pech, Optimum Taxation of Life Annuities, January 2006

1643 Naércio Aquino Menezes Filho, Marc-Andreas Muendler and Garey Ramey, The Structure of Worker Compensation in Brazil, with a Comparison to France and the United States, January 2006

1644 Konstantinos Angelopoulos, Apostolis Philippopoulos and Vanghelis Vassilatos, RentSeeking Competition from State Coffers: A Calibrated DSGE Model of the Euro Area, January 2006

1645 Burkhard Heer and Bernd Suessmuth, The Savings-Inflation Puzzle, January 2006

1646 J. Stephen Ferris, Soo-Bin Park and Stanley L. Winer, Political Competition and Convergence to Fundamentals: With Application to the Political Business Cycle and the Size of Government, January 2006

$1647 \mathrm{Yu}-\mathrm{Fu}$ Chen, Michael Funke and Kadri Männasoo, Extracting Leading Indicators of Bank Fragility from Market Prices - Estonia Focus, January 2006

1648 Panu Poutvaara, On Human Capital Formation with Exit Options: Comment and New Results, January 2006

1649 Anders Forslund, Nils Gottfries and Andreas Westermark, Real and Nominal Wage Adjustment in Open Economies, January 2006

1650 M. Hashem Pesaran, Davide Pettenuzzo and Allan G. Timmermann, Learning, Structural Instability and Present Value Calculations, January 2006

1651 Markku Lanne and Helmut Luetkepohl, Structural Vector Autoregressions with Nonnormal Residuals, January 2006

1652 Helge Berger, Jakob de Haan and Jan-Egbert Sturm, Does Money Matter in the ECB Strategy? New Evidence Based on ECB Communication, January 2006

1653 Axel Dreher and Friedrich Schneider, Corruption and the Shadow Economy: An Empirical Analysis, January 2006

1654 Stefan Brandauer and Florian Englmaier, A Model of Strategic Delegation in Contests between Groups, January 2006 
1655 Jan Zápal and Ondřej Schneider, What are their Words Worth? Political Plans and Economic Pains of Fiscal Consolidations in New EU Member States, January 2006

1656 Thiess Buettner, Sebastian Hauptmeier and Robert Schwager, Efficient Revenue Sharing and Upper Level Governments: Theory and Application to Germany, January 2006

1657 Daniel Haile, Abdolkarim Sadrieh and Harrie A. A. Verbon, Cross-Racial Envy and Underinvestment in South Africa, February 2006

1658 Frode Meland and Odd Rune Straume, Outsourcing in Contests, February 2006

1659 M. Hashem Pesaran and Ron Smith, Macroeconometric Modelling with a Global Perspective, February 2006

1660 Alexander F. Wagner and Friedrich Schneider, Satisfaction with Democracy and the Environment in Western Europe - a Panel Analysis, February 2006

1661 Ben J. Heijdra and Jenny E. Ligthart, Fiscal Policy, Monopolistic Competition, and Finite Lives, February 2006

1662 Ludger Woessmann, Public-Private Partnership and Schooling Outcomes across Countries, February 2006

1663 Topi Miettinen and Panu Poutvaara, Political Parties and Network Formation, February 2006

1664 Alessandro Cigno and Annalisa Luporini, Optimal Policy Towards Families with Different Amounts of Social Capital, in the Presence of Asymmetric Information and Stochastic Fertility, February 2006

1665 Samuel Muehlemann and Stefan C. Wolter, Regional Effects on Employer Provided Training: Evidence from Apprenticeship Training in Switzerland, February 2006

1666 Laszlo Goerke, Bureaucratic Corruption and Profit Tax Evasion, February 2006

1667 Ivo J. M. Arnold and Jan J. G. Lemmen, Inflation Expectations and Inflation Uncertainty in the Eurozone: Evidence from Survey Data, February 2006

1668 Hans Gersbach and Hans Haller, Voice and Bargaining Power, February 2006

1669 Françoise Forges and Frédéric Koessler, Long Persuasion Games, February 2006

1670 Florian Englmaier and Markus Reisinger, Information, Coordination, and the Industrialization of Countries, February 2006

1671 Hendrik Hakenes and Andreas Irmen, Something out of Nothing? Neoclassical Growth and the 'Trivial' Steady State, February 2006 
1672 Torsten Persson and Guido Tabellini, Democracy and Development: The Devil in the Details, February 2006

1673 Michael Rauber and Heinrich W. Ursprung, Evaluation of Researchers: A Life Cycle Analysis of German Academic Economists, February 2006

1674 Ernesto Reuben and Frans van Winden, Reciprocity and Emotions when Reciprocators Know each other, February 2006

1675 Assar Lindbeck and Mats Persson, A Model of Income Insurance and Social Norms, February 2006

1676 Horst Raff, Michael Ryan and Frank Staehler, Asset Ownership and Foreign-Market Entry, February 2006

1677 Miguel Portela, Rob Alessie and Coen Teulings, Measurement Error in Education and Growth Regressions, February 2006

1678 Andreas Haufler, Alexander Klemm and Guttorm Schjelderup, Globalisation and the Mix of Wage and Profit Taxes, February 2006

1679 Kurt R. Brekke and Lars Sørgard, Public versus Private Health Care in a National Health Service, March 2006

1680 Dominik Grafenhofer, Christian Jaag, Christian Keuschnigg and Mirela Keuschnigg, Probabilistic Aging, March 2006

1681 Wladimir Raymond, Pierre Mohnen, Franz Palm and Sybrand Schim van der Loeff, Persistence of Innovation in Dutch Manufacturing: Is it Spurious?, March 2006

1682 Andrea Colciago, V. Anton Muscatelli, Tiziano Ropele and Patrizio Tirelli, The Role of Fiscal Policy in a Monetary Union: Are National Automatic Stabilizers Effective?, March 2006

1683 Mario Jametti and Thomas von Ungern-Sternberg, Risk Selection in Natural Disaster Insurance - the Case of France, March 2006

1684 Ken Sennewald and Klaus Waelde, "Itô's Lemma" and the Bellman Equation for Poisson Processes: An Applied View, March 2006

1685 Ernesto Reuben and Frans van Winden, Negative Reciprocity and the Interaction of Emotions and Fairness Norms, March 2006

1686 Françoise Forges, The Ex Ante Incentive Compatible Core in Exchange Economies with and without Indivisibilities, March 2006

1687 Assar Lindbeck, Mårten Palme and Mats Persson, Job Security and Work Absence: Evidence from a Natural Experiment, March 2006 
1688 Sebastian Buhai and Coen Teulings, Tenure Profiles and Efficient Separation in a Stochastic Productivity Model, March 2006

1689 Gebhard Kirchgaessner and Silika Prohl, Sustainability of Swiss Fiscal Policy, March 2006

1690 A. Lans Bovenberg and Peter Birch Sørensen, Optimal Taxation and Social Insurance in a Lifetime Perspective, March 2006

1691 Moritz Schularick and Thomas M. Steger, Does Financial Integration Spur Economic Growth? New Evidence from the First Era of Financial Globalization, March 2006

1692 Burkhard Heer and Alfred Maussner, Business Cycle Dynamics of a New Keynesian Overlapping Generations Model with Progressive Income Taxation, March 2006

1693 Jarko Fidrmuc and Iikka Korhonen, Meta-Analysis of the Business Cycle Correlation between the Euro Area and the CEECs, March 2006

1694 Steffen Henzel and Timo Wollmershaeuser, The New Keynesian Phillips Curve and the Role of Expectations: Evidence from the Ifo World Economic Survey, March 2006

1695 Yin-Wong Cheung, An Empirical Model of Daily Highs and Lows, March 2006

1696 Scott Alan Carson, African-American and White Living Standards in the $19^{\text {th }}$ Century American South: A Biological Comparison, March 2006

1697 Helge Berger, Optimal Central Bank Design: Benchmarks for the ECB, March 2006

1698 Vjollca Sadiraj, Jan Tuinstra and Frans van Winden, On the Size of the Winning Set in the Presence of Interest Groups, April 2006

1699 Martin Gassebner, Michael Lamla and Jan-Egbert Sturm, Economic, Demographic and Political Determinants of Pollution Reassessed: A Sensitivity Analysis, April 2006

1700 Louis N. Christofides and Amy Chen Peng, Major Provisions of Labour Contracts and their Theoretical Coherence, April 2006

1701 Christian Groth, Karl-Josef Koch and Thomas M. Steger, Rethinking the Concept of Long-Run Economic Growth, April 2006

1702 Dirk Schindler and Guttorm Schjelderup, Company Tax Reform in Europe and its Effect on Collusive Behavior, April 2006

1703 Françoise Forges and Enrico Minelli, Afriat's Theorem for General Budget Sets, April 2006 